\title{
PADRONIZAÇÃO DO EXAME TERMOGRÁFICO NAS ARTICULAÇÕES DO CARPO E MATACARPOFALANGEANAS DE CAVALOS EM TREINAMENTO
}

\author{
Luis Fagner Silva Machado ${ }^{1}$, Rosangela Locatelli Dittrich², Mariana Pavelski², \\ Amanda Moser Coelho da Fonseca Afonso ${ }^{1}$, Ivan Deconto², Peterson Triches \\ Dornbusch ${ }^{2}$ \\ 1 FURB \\ 2 UFPR \\ Correspondência: Mariana Pavelski: mari_medvet@hotmail.com
}

\begin{abstract}
RESUMO: A termografia é um exame por imagem que consiste em captar as radiações térmicas emitidas por um corpo ou objeto e as transformar num mapa térmico da temperatura superficial dos mesmos. Por ser uma técnica recente em medicina veterinária, e não existirem valores de referência quanto à temperatura de estruturas anatômicas e temperatura ambiente, seu uso é limitado. Com o objetivo de determinar os valores de referência para temperatura da articulação do carpo e metacarpofalangeana do membro torácico direito (MTD), foram utilizados 45 equinos em treinamento da raça crioula, sadios, a temperatura foi aferida em dois períodos do dia (manhã e tarde). Foram também avaliados a correlação da variação da temperatura ambiente com as temperaturas da articulação do carpo MTD e MTE e a comparação da temperatura média das articulações metacarpofalangeana (MTD e MTE) articulação do carpo (MTD e MTE). As temperaturas para a articulação do carpo e articulação metacarpofalangeana apresentaram diferenças com a variação da temperatura ambiente. A comparação da temperatura média das articulações não demonstrou diferença significativa entre as temperaturas.
\end{abstract}

Palavras-chave: termografia; eqüino; articulação

\section{STANDARDIZATION OF THERMOGRAPHIC EXAMINATION IN JOINTS OF HORSES IN TRAINING}

\begin{abstract}
Thermography is a diagnostic imaging tool, which captures the thermal radiation emitted by a body or object, and turn into a thermal map of its surface temperature. The use in veterinary medicine is limited, because this is a recent technique, few professionals have the thermal imager and there are no reference values, as anatomical structures and ambient temperatures. The aim of this study was to determine de reference values of carpal and the metacarpophalangeal joint, in the right forelimb. A total of 45 healthy Criollo breed horses in training were used, the measures was done in two periods of the day (morning and afternoon). There were also evaluated the correlation of temperature with ambient temperatures of the carpal joint of the right forelimb and left forelimb, and the comparison of the average temperature of the metacarpophalangeal joints and carpal, carpal joint and carpal, metacarpophalangeal joint and metacarpophalangeal. The carpal and metacarpophalangeal joint had differences with the variation of the environment temperature. The comparison of the average temperature of the joints showed no significant difference between the temperatures.
\end{abstract}

Key Words: thermography; equine; joint 


\section{INTRODUÇÃO}

$\mathrm{Na}$ clínica de equinos, principalmente na categoria de animais de alto desempenho esportivo, os problemas relacionados ao sistema locomotor representam grande parte dos atendimentos clínicos veterinários. Estes problemas podem causar danos graves ao animal, encurtar ou interromper a sua vida esportiva.

Os traumas diretos e indiretos são as causas mais importantes de afecção articular nos equinos e o conceito etiológico central mais amplamente aceito é o de "trauma por uso" (Mcllwraith, 1994). O estresse excessivo sobre a cartilagem sadia e o estresse normal sobre a cartilagem anormal podem iniciar o processo (Mcllwraith, 2000). As articulações estão continuamente sujeitas a movimentos anormais que causam intensa compressão sobre suas estruturas (Rasera, 2007).

O desempenho do cavalo atleta depende do bom estado do sistema locomotor. Quando ocorrem lesões neste sistema, diagnóstico precoce é importante para tratamento, prognóstico e monitoramento adequados.

A análise do líquido sinovial e o exame radiográfico não possibilitam a determinação precoce das enfermidades articulares (Yancik et al., 1987) havendo a necessidade da associação de outros métodos de diagnóstico.

O exame radiográfico pode indicar as lesões ósseas apenas após 45 dias, as quais são consequentes da destruição da cartilagem articular e do envolvimento ósseo secundário. Devido a isto, as mudanças iniciais da doença degenerativa articular podem não serem observadas nas radiografias (Morgan, 1968). A carga imposta aos tecidos articulares nos equinos em treinamento pode provocar sinovite. Sua maior intensidade ocorre três horas após o término da atividade esportiva e retorna aos valores basais após 24 horas. Com a persistência da inflamação, a consequência é o desenvolvimento da osteoartrite ou doença degenerativa articular, com perda da função e queda do desempenho atlético (Rasera, 2007).

A termografia é uma ferramenta de imagem diagnóstica extremamente útil de lesões agudas e lesões subclínicas. Consiste em técnica não invasiva que capta a emissão de calor da superfície do corpo pela radiação infravermelha, indicando a temperatura da superfície corporal (Turner, 1991).

Segundo Sage (2002) e Turner (2001) a termografia, a anestesia regional e intraarticular e o exame físico relacionam-se satisfatoriamente para o diagnóstico na claudicação da articulação metacarpofalangeana de equinos.

A termografia tem sido pouco utilizada na rotina clínica, pela carência do equipamento e/ou desconhecimento da técnica, outros fatores são a falta de valores de referência, a falta de padronização do uso da técnica em ambientes não climatizados ou a necessidade de um local fechado climatizado para realização do exame termográfico.

Os objetivos deste trabalho foram de padronizar o exame por termografia das articulações metacarpofalangeana e do carpo de cavalos sadios em treinamento, estabelecer as temperaturas fisiológicas normais destas articulações e correlacionar com a temperatura ambiente em três regiões distintas e comparar a temperatura média destas articulações.

\section{MATERIAL E MÉTODOS}

Quarenta e cinco equinos em treinamento da raça Crioula foram utilizados no estudo (22 machos e 23 fêmeas), adultos com idade entre 4 a 10 

de cavalos em treinamento

anos, hígidos e selecionados com base na inexistência de queixa de claudicação anterior ou outras enfermidades do sistema locomotor identificadas principalmente por meio de exame físico e de esforço. Os animais eram de três criatórios localizados, nos municípios de Jaraguá do Sul/SC, Gaspar/SC e Araucária/PR.

$\mathrm{Na}$ véspera da avaliação termográfica (24 horas), os animais foram submetidos ao exame físico completo, com avaliações específicas do sistema locomotor. Foram realizadas avaliação visual dos animais em repouso e em exercício (trote e galope), palpação e manipulação das estruturas do sistema locomotor, exame da sensibilidade das articulações ao exame de flexão e do casco ao pinçamento, com pinça tenaz de casco. O exame visual do cavalo em repouso observou atitudes e posturas anormais, edemas, solução de continuidade, aumentos de volume, alterações de coloração da pele, simetria, aprumos e observação sobre o apoio dos membros. As flexões das articulações foram realizadas durante um minuto e meio, e posteriormente o animal era submetido ao trote. $O$ trote $e$ galope foram realizados em pista reta com piso rígido, numa distância de 100 metros e em seguida o animal foi trotado em círculo num redondel de areia durante cinco minutos, para ambos os lados. Após o exame em repouso, todas as características dos andamentos (passo e trote) e da movimentação dos membros foram observadas à inspeção. O objetivo principal em exercitar o cavalo foi identificar o membro (ou membros) afetado e o grau de claudicação e incoordenação do movimento segundo Stashak (1994).

Os animais foram mantidos individualmente em baias 24 horas antes do exame termográfico, ao abrigo da luz solar e correntes de ar. A temperatura ambiente (TA) e a umidade relativa do ar (URA) foram mensuradas individualmente nas baias onde foram realizados os exames, utilizando um medidor de temperatura e umidade portátil Vaisala HUMICAP ${ }^{\circledR} \mathrm{HM} 34$.

Os exames termográficos das articulações metacarpofalângicas (MTF) e dos carpos (CAR) foram realizados nos membros torácicos direito de 30 animais e nos membros torácicos direito e esquerdo de 15 animais. O método para obtenção das imagens termográficas foi o método estático, segundo Herrick (2004), em que as imagens do paciente são obtidas logo após aclimatação térmica. As imagens termográficas foram obtidas a distância média de $1,5 \mathrm{~m}$ com 0 animal em posição quadrupedal. A câmera termográfica utilizada para o exame termográfico foi à câmera portátil "Bcam Flir system", $\left(F^{\prime} \mathrm{YR}^{\circledR}\right)$.

Os horários de avaliação foram divididos em dois períodos, manhã (05h30min às 07h00min) e tarde (12h00min às 16h00min).

A análise estatística foi descritiva e calcularam-se as médias e o erro padrão da média (EPM). Sobre as articulações do carpo (CAR) e metacarpofalangeana (MTF) dos membros torácicos direito (MTD) e esquerdo (MTE), e a temperatura ambiente (TA) foi estimado o coeficiente de correlação. Realizou-se a análise de regressão com o objetivo de comparar a temperatura das articulações do mesmo membro e do membro colateral e a temperatura ambiente. O programa estatístico utilizado foi o Graphpad prism v.5.

\section{RESULTADOS E DISCUSSÃO}

As variações de temperatura em graus Celsius das articulações do carpo MTD, metacarpofalangeana MTD e da temperatura ambiente, percentual de umidade relativa do ar (URA), média e erro padrão da média (EPM) nos 
municípios de Araucária - PR, Jaraguá do Sul - SC e Gaspar - SC estão apresentadas na Tabela 1.

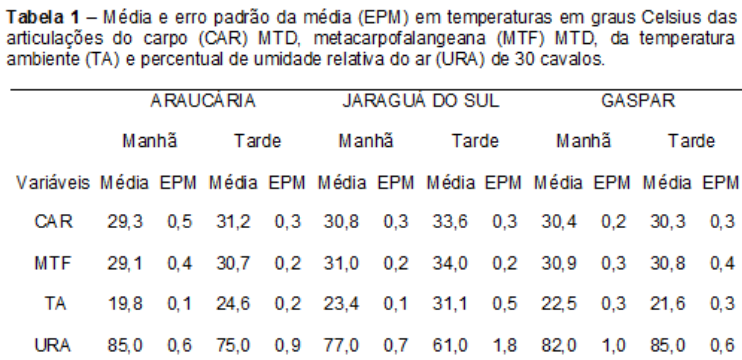

As temperaturas das articulações do carpo e metacarpofalangeana foram similares nos três municípios, havendo correlação no aumento e diminuição de temperatura destas articulações em relação à oscilação da temperatura ambiente. A diferença mínima entre estas articulações ocorreu quando a temperatura ambiente encontrava-se próximo aos $20^{\circ} \mathrm{C}$. Este resultado foi similar aos encontrados por Brioschi et al., (2007), em que para o diagnóstico de afecções articulares em humanos a temperatura ambiente deve ser de $18^{\circ} \mathrm{C}$. Segundo Briosch et al., (2007) e Bezerra (2007), no exame termográfico geral os pacientes humanos devem permanecer em temperatura ambiente de $19^{\circ}$ a $22^{\circ} \mathrm{C}$, corrente de ar $<0,2 \mathrm{~m} / \mathrm{s}$, e distância média de $1,5 \mathrm{~m}$ da câmara termográfica, sem exposição ao sol e atividades físicas extenuantes 24 horas anteriores ao exame.

As condições do meio externo para o exame termográfico das articulações do carpo e metacarpofalangeana foram devidamente apropriadas sem movimentação, atividades físicas, radiação solar e exposição a correntes de ar nas últimas 24 horas. Alguns fatores podem variar a temperatura da pele, como movimentos, radiação de energia externa (sol), temperatura ambiental e fluxo de ar (Turner, 1991). Neste experimento a variação de temperatura ambiente influenciou a temperatura das articulações, mas sem comprometer a fidedignidade das temperaturas articulares encontradas pelo exame termográfico (Figura 1).

A articulação com menor temperatura foi a metacarpofalangeana $(29,1 \stackrel{\circ}{-})$ no turno da manhã no município de Araucária - PR, com temperatura ambiente de 19,8 $\stackrel{\circ}{\mathrm{C}}$. A articulação com maior temperatura foi a metacarpofalangeana $\left(34,0^{\circ} \mathrm{C}\right)$ no turno da tarde no município de Jaraguá do Sul - SC, com temperatura ambiente de $31,1^{\circ} \mathrm{C}$ (Tabela 2$)$.

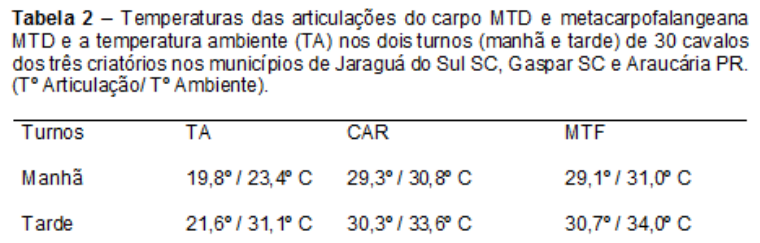

Segundo Castro et al. (2010) as particularidades térmicas de algumas regiões tornam-se comprometidas nas temperaturas ambientais acima de $30^{\circ} \mathrm{C}$, em que a vasodilatação cutânea não é suficiente para aumentar a dissipação do calor corporal do animal, levando ao aumento generalizado da mesma e, consequentemente à modificação do padrão térmico fisiológico, tornando as imagens mais homogêneas na câmera termográfica. Entretanto, neste estudo não houve comprometimento das imagens termográficas obtidas em temperatura ambiente superior a $30^{\circ} \mathrm{C}$. As temperaturas das articulações estudadas demonstraram diferença significativa com aumento da temperatura ambiente, ou seja, conforme a temperatura ambiente aumentou a temperatura da articulação também aumentou isoladamente.

A maioria das articulações são melhor avaliadas no exame termográfico no aspecto dorsal (Turner, 2001), como verificado no presente estudo, porque não houve variações e interferências da temperatura por estruturas anatômicas 
adjacentes as articulações no aspecto medial e lateral.

Os valores da temperatura ambiente obtidos nos três municípios tiveram correlação positiva conforme a temperatura das articulações do carpo (MTD) (Figura. 1A) e (MTE) (Figura. 1B). Percebe-se a tendência ao aumento da temperatura das articulações do carpo (MTD e MTE), à medida que a temperatura ambiente aumenta.
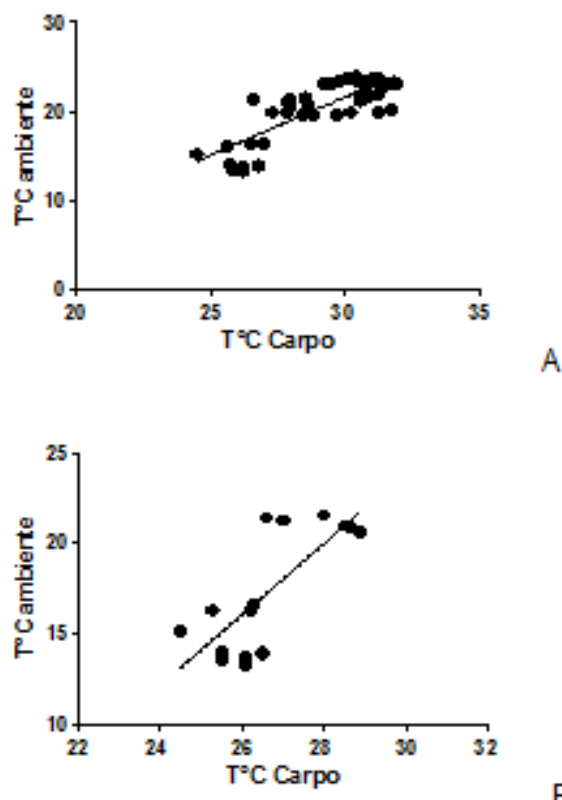

$\mathrm{B}$

Figura 1 - Análise de regressão linear da temperatura ambiente e das articulações do carpo (MTD) (A) de 45 cavalos $\left(R^{2}=0,6594\right)$ e (MTE) (B) de 15 cavalos $\left(R^{2}=0,5789\right)$.

A análise comparativa da temperatura média das articulações metacarpofalangeana (MTD e MTE) (Figura. 2A), articulação do carpo (MTD e MTE) (Figura. 2B), e comparação da temperatura entre carpos e metacarpofalangeanas (MTD) (Fig. 2C), não demonstraram diferença significativa, sendo que a diferença média de temperatura entre as articulações do carpo (MTD e MTE) foi de 0,44 $\pm 0,39$ ( $p>0,0001)$, e entre as articulações metacarpofalangeanas (MTD e MTE) foi de 0,45 $\pm 0,30$ ( $p>0,0001)$, desta forma a comparação entre 0 membro colateral serve de parâmetro para julgar a normalidade da articulação, segundo descrito por Turner (2001).

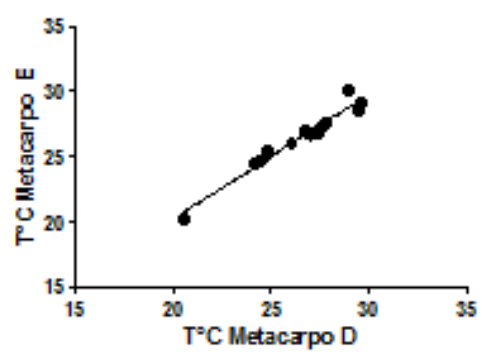

A

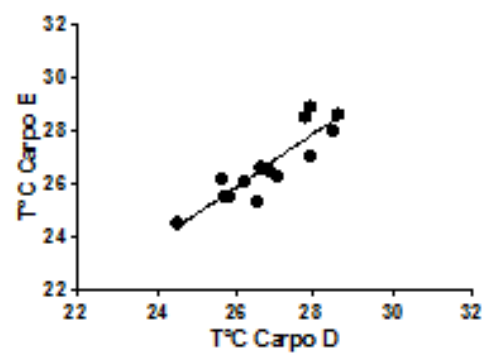

B

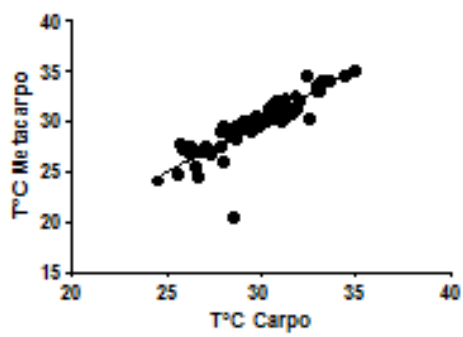

Figura 2 - Análise de regressão linear das temperaturas da articulação metacarpofalangeana (MTD) e (MTE) de 15 cavalos $\left(R^{2}=0,9502\right)$ (A), articulação do carpo (MTD) e (MTE) de 15 cavalos $\left(R^{2}=0,8017\right)(B)$ e articulação metacarpofalangeana (MTD) e articulação do carpo (MTD) de 150 articulações de 45 cavalos $\left(R^{2}=0,7702\right)$.

A termografia é capaz de acusar variação de temperatura a partir de 0,2 graus $\mathrm{C}^{\circ}$, ou seja, até quando não se percebe ao exame de palpação da região (Turner et al., 2004). Este fator explica a importância dos cuidados com o ambiente e com o animal para a realização do exame termográfico.

\section{CONCLUSÃO}

A termografia infravermelha pode ser uma ferramenta diagnóstica 
complementar útil na avaliação das articulações do carpo e matacarpofalangeanas em cavalos atletas na rotina clínica.

Há correlação positiva entre a temperatura ambiente e termográfica, de forma que não podem ser comparadas as temperaturas corporais obtidas em diferentes momentos onde a temperatura ambiente não está padronizada.

No caso de suspeita de enfermidade articular sugere-se a comparação da temperatura do membro colateral como referência para determinar se uma das articulações em estudo apresenta anormalidades além de relacionar os achados com exame físico.

\section{NOTAS INFORMATIVAS}

Este trabalho foi submetido $\mathrm{e}$ aprovado pela Comissão de Ética no Uso de Animais CEUA/SCA, protocolo 051/2010.

\section{REFERÊNCIAS}

BEZERRA, L. A., et al. Uma comparação entre temperaturas de mamas obtidas pelo método dos volumes finitos em malhas não estruturadas e aquelas adquiridas através de termogramas de pacientes de hospital público localizado em clima tropical. Anais do VIII Congresso Ibericoamericano de Engenharia Mecânica, Cusco, Peru, 2007.

BEZERRA, L. L. Uso de imagens termográficas em tumores mamários para validação de simulação computacional. 2007. Dissertação de Mestrado.Programa de Pós Graduação em Engenharia Mecânica - Universidade Federal de Pernambuco.

BRIOSCHI, M. L, et al. Termometria cutânea: novos conceitos. Jornal Vascular Brasileiro, v.2, n.2, p.151-160, 2003

BRIOSCHI, M. L., et al. Utilização da imagem infravermelha em reumatologia. Revista Bras. de Reumatologia, v.47, n.1, p.42-51, 2007.

CASTRO, V., et al. Padrão termográfico de equinos hígidos em diferentes temperaturas ambientais. Revista Brasileira de Medicina Veterinária Equina, v.5, n.29, p.4-7, 2010.

HERRICK. A. L. HUTCHINSON, C. Vascular imaging. Best Practice \& Research Clinical Rheumatology, v.18, n.6, p.957-979, 2004.

McILWRAITH, C. W. Doenças das articulações, tendões, ligamentos e estruturas relacionadas. In: STASHAK, T.S. (ed). Claudicação em eqüinos segundo Adams. 4 ed. São Paulo: Roca, 1994. Cap. 7, p. 350-502.

McILWRAITH, C. W. Osteoarthritis (Degenerative Joint Disease). In: Bain-Fallon Memorial Lectures, 22., 2000, Melbourne.

Proceedings... Artarmon: Australian Equine Veterinary Association, 2000. p. 46-96, 2000.

MORGAN, J.P. Radiographic diagnosis of boné and joint diseases in the horse. Cornell Vet, v.58, p.28-47, 1968.

NATIONAL RESEARCH COUNCIL - NRC.

Nutrient requirements of horse, 6 ed.

Washington: National Academy Press, 2007.

RASERA, L. Influência da atividade física sobre a articulação metacarpofalangeana de cavalos de pólo. 2007. Tese de Doutorado. Programa de Pós Graduação em Medicina Veterinária - Faculdade de Medicina Veterinária e Zootecnia da Universidade de São Paulo.

RASERA, L., et al. Alterações radiográficas e ultra-sonográficas iniciais em osteoartrite experimental eqüina. Arquivo Bras de Med Vet e Zootecnia, v.59, n.3, p.634-640, 2007.

SAGE, A.M.; TURNER, T.A. Ultrasonography of the soft tissue strutures of the equine foot. Equine Vet. Educ., v.14, p.212-221, 2002.

STASHAK, T. S. Claudicação em Equinos Segundo Adams. São Paulo, Editora Roca LTDA, 1994 p. 351-451. 4v.

TURNER, T.A. Thermography as aid to the clinical lameness evaluation. Veterinary Clinics of North America. Equine Practice, v.7, n.2, p.311-338. 1991.

TURNER, T. A. Diagnostic thermography. Veterinary Clinics of North America. Equine Practice, v.17, p.95-113. 2001.

TURNER, T. A.; WALDSMITH, J. K.; WILSON, J. H.; How to assess saddle fit in horses. Annual Convention of the American Association of Equine Practitioners, 2004, Denver, Colorado, USA.

YANCIK, S.A., et al. Evaluation of creatine kinase and lactate dehydrogenase activities in clinically normal and abnormal equine joint. Am J Vet Res, v.48, n3, p.463-66, 1987. 